\title{
Study of the properties of sulfonic cation exchanger
}

\author{
Dilfuza Nuriddinova $^{1 *}$, Farkhod Yusupov $^{2}$, and Bobomurod Xursandov ${ }^{2}$ \\ ${ }^{1}$ Karshi State University, Karshi, Uzbekistan \\ ${ }^{2}$ Institute of general and inorganic chemistry of Academy of Science of Republic of Uzbekistan, \\ Tashkent, Uzbekistan
}

\begin{abstract}
In this research work, we have firstly synthesized the sulfonated polyvinyl chloride cation exchanger based on local raw materials. It was firstly created syntheses methodology of the sulfonated polyvinyl chloride cation exchanger and determined syntheses reaction parameters. It was first investigated that thermodynamics of synthesized the sulfonated polyvinyl chloride cation exchanger: kinetics, sorption isotherms, change of thermodynamics function (Gibbs energy, Entropy, and Entalpy). DFT calculation of synthesized the sulfonated polyvinyl chloride cation exchanger: energy difference between LUMO and HOMO molecular orbitals, Chemical Hardness $(\eta)$, Electronegativity $(\chi)$, Electronic chemical potential $(\mu)$, Global electrophilicity Index $(\omega)$ and Chemical Softness (s) were firstly computed. We have used thermodynamic methods in doing thermodynamics research. The Frontier molecular orbital method was used on doing DFT calculation by 6-311G $(\mathrm{d}, \mathrm{p})$ basis set. These firstly synthesized the sulfonated polyvinyl chloride cation exchanger based on local raw materials is very cheap and effective; it will be used in the chemical industry for softening or cleaning waste water from $\mathrm{Ca}^{2+}$ or $\mathrm{Mg}^{2+}$ ions and different heavy ions. Electrochemical impedance measurements show that the quasisubstitution process has become between $\mathrm{Mg}^{+2}$ and $\mathrm{Ca}^{+2}$ ions and $\mathrm{Na}+$ on the sulfonated polyvinyl chloride cation exchanger in the result of which growth of charge transfer and dielectric constant of mediums. Investigating thermodynamic parameters of this compound will be used for some purposes: a deep understanding of the thermodynamics of sorption processes and using determined thermodynamics in real production processes of water softened materials. DFT calculation investigating gives a deep understanding of how thermodynamics properties can depend on the molecular structure of water softened polymer materials.
\end{abstract}

*Corresponding author: dnuriddinova@list.ru 


\section{Introduction}

One of the urgent problems of environmental protection is the treatment and reuse of industrial wastewater from oil and gas processing. Nowadays used wastewater recycling technology is very expensive, require high cost technological equipment, and someone is danger for environment. The use these kinds of technology for under developed countries are economically difficult [1-3].

Nowadays water used triple than past, many factors polluted water with danger chemicals and growth numbers of people around world are seriously problems, according to UNEP information. Water pollution and population growth in urban areas are significant problem for developing nations [4-5].

International Oil and Gas Organization claimed that industrial waste water is formed in the oil and gas industry when drill oil and gas wells, extracting processes of oil and gas occur, wash wells, cool heat exchangers, the chemical processes in reactors and the corrosion of equipment occur. In addition to this, industrial wastewater is formed in the water supply system of gas processing and cleaning, using and preserving chemical reagents. When waste water is accumulated it is polluted with various residues of oil and oil products such as aliphatic, aggressive gases, aromatic hydrocarbons, heavy soluble and non-dissolving metals in water. In addition to this, hydrocarbon waste in the composition of waste water seriously affects the human body, animals, plants, and destroys the ecological balance, according to World Health Organization. To carry out these vital problems, in recent years, researchers have been paying more and more attention to creating the recycling methods for industrial wastewater. Some scientists suggest that the precipitation, electrolysis, filtration, sorption, biosorption methods is more efficient [6-8].

It most said that the important characteristic of industrial wastewater is its hardness, which it is link with calcium or magnesium ions in water. To decrease the hardness of calcium or magnesium ions in water is very important for solve above problem. $1 \mathrm{Mg} \div$ eq/1 wastewater hardness concentrations are equaled respectively $20.04 \mathrm{mg}$ of $\mathrm{Ca}^{2+}$ or $12.16 \mathrm{mg}$ of $\mathrm{Mg}^{2+}$ ions, it responds to the requirement of reuse of purified water in the workplace. In industry, water hardness is more than 12-17 $\mathrm{mg} \div \mathrm{eq} / 1$. The minimal hardness standard is $1.6-3.0 \mathrm{mg} \div \mathrm{eq} / 1$ according to (SANPIN 2.1.4.1116-02) Potable Water - Hygienic Requirements for Quality of Bottled Water - Quality Control (Russian Federation) [9-10].

Practical results show when the concentrations of $\mathrm{Ca}^{2+}$ or $\mathrm{Mg}^{2+}$ ions increase the amount of accumulation sediment in the water supply system, heat exchangers and household appliances on plumbing fixes also growths. High concentration of $\mathrm{Ca}^{2+}$ or $\mathrm{Mg}^{2+}$ ions cover metal surface as a salt deposits: $\mathrm{CaCl}_{2}, \mathrm{CaSO}_{4}, \mathrm{MgCl}_{2}, \mathrm{MgSO}_{4}$, $\mathrm{CaCO}_{3}$ and $\mathrm{MgCO}_{3}$. Accumulated sediment salts on the metal surface corrode metal materials. Low concentration of metal ions $(0.5 \mathrm{mg} \div \mathrm{Eq} / \mathrm{l})$ causes corrosive activity, meaning that the metal materials were destroyed. At this processes low concentration metal ions have corrosive role on corrosion reactions which require activity iron ions, low concentration of $\mathrm{Ca}^{2+}$ or $\mathrm{Mg}^{2+}$ ions can increase activity degree of iron ions [11-14].

It is known that the process of wastewater recycling treatment is carried out by several methods:

*thermal method, which it is carried out based on the heating of waste water, next distillation or freezing of waste water; 
* precipitation method, in this method, $\mathrm{Ca}^{2+}$ or $\mathrm{Mg}^{2+}$ ions in wastewater are precipitated with chemical reagents, these ions are changed to insoluble chemical compounds through chemical reagents as a results they are bound from water;

*ion exchanging method, this method is carried out by that $\mathrm{Ca}^{2+}$ or $\mathrm{Mg}^{2+}$ ions in wastewater are exchanged with $\mathrm{Na}^{+}$or $\mathrm{H}^{+}$ions, this action is done by the help of special materials (ion exchanger);

*dialysis, in this last method, $\mathrm{Ca}^{2+}$ or $\mathrm{Mg}^{2+}$ ions in wastewater are changed to colloid chemical compounds which have minus and plus charge so these charged $\mathrm{Ca}^{2+}$ or $\mathrm{Mg}^{2+}$ ions colloid compounds are separated water through electrodes.

An unconventional method of cleaning wastewater from residues-fractions of petroleum products and sludge is the use of the latest nanotechnology achievement. In this case, an allotropic modification of carbon graphite $(1 \mathrm{~nm})$ is used as a sorbent, given that $1 \mathrm{~g}$ of graphite absorbs $60 \mathrm{~g}$ of oil residue, it great capacity, but they require high cost technological equipment [15-17].

In this research work, it was used low cost and more efficient waste water recycling methods and materials. The purpose of this research work is that synthesis polyvinyl chloride cation exchanger sorbents and develops the water softening and recycle technology for the industrial wastewater. This is carried out by using complex ion-exchange polymers and the creation environmentally friendly technologies that ensure the purification industrial effluents of petrochemical production in order to ensure recycled water resources.

\section{Methods}

\subsection{Thermodynamic methods}

During this investigation, it was used the methods of precipitation and extraction to determine the mass of non-desorbed ions and the adsorption capacity of the sorbent. It was determined the concentration of $\mathrm{NaCl}, \mathrm{CaCl}_{2}, \mathrm{MgCl}_{2}$ and other products in water before and after adsorption by chromatographic and gravimetric analyses.

In this research work, the water recycling methods have been developed for obtaining new polyvinyl chloride cation exchanger on the basis of sulfur-containing compounds and plastic polyvinyl chloride. In this investigation work the following methods and action were used; in the beginning of processes, the waste water is purified from solid dispersed colloidal particles by sedimentation, next the organic substances, oil and oil products in wastewater extracted with hexane and adsorbed through the composition included the activated carbon, chalk and Muborak (Uzbekistan region) soil in the ratio 15: 2: 1.25. Afterwards the degree of water purification from the oil product, the adsorption and the equilibrium concentration of the oil product were calculated under static conditions. Lastly, water is purified from calcium and magnesium ions $\left(\mathrm{Ca}^{+2}, \mathrm{Mg}^{+2}\right)$ by the help of sulfonic cation exchanger.

The sorption properties of the sulfonated polyvinyl chloride cation exchanger were calculated in calcium and magnesium chloride solutions were studied. These experiments were carried out in 24 hours in calcium and magnesium chloride artificial solutions with a concentration from 0.025 to $0.1 \mathrm{~mol} / 1.0 .3 \mathrm{~g}$ dry sorbent was placed in a $250 \mathrm{ml}$ conical flask and $100 \mathrm{ml}$ of $\mathrm{CaCl}_{2}$ or $\mathrm{MgCl}_{2}$ solution at various concentrations were added. The initial concentration and its change after sorption were determined by the analytic complexometric titration method. 
The adsorption amounts of $\mathrm{Ca}^{2+}$ and $\mathrm{Mg}^{2+}$ ions were calculated using following equation:

$$
q_{e}=\frac{\left(C_{o}-C_{e q}\right) V}{m}
$$

Here, $q_{e}$ is the amount of ion which is absorbed by the ion exchanger, at $\mathrm{mmol} / \mathrm{g} ; C_{o}$ is the initial concentration, at $\mathrm{mmol} / \mathrm{l} ; C_{e q}$ is the equilibrium concentration, mmol/1; $V$ is the volume of the softened solution, at $1 ; m$ is the mass of dry sorbent at $g$.

\subsection{Syntheses of the sulfonated polyvinyl chloride cation exchanger}

The main characteristic of this research is that the sulfonated polyvinyl chloride cation exchanger because it has great ability for sorption capacity for $\mathrm{Ca}^{2+}$ and $\mathrm{Mg}^{2+}$ ions. What stands out from Table I highlights that sulfonic cation exchangers reaction properties. It is clear from this given information on this table plastic polyvinyl chloride with powdered sulfur and sulfur-containing compounds were modified at four ratios; 10:7, 9:8, 8:9 and 7:10. Results indicate last two (sulfur dominated) modifications have over $11 \mathrm{~g}$ sulfonic cation exchanger, in these reaction ratios the productivity is larger than other. Next pattern is that last two (sulfur dominated) sulfonic cation exchangers modifications statistical exchanged $(\mathrm{SChV}) 3.58$ and $3.78 \mathrm{mg} \div \mathrm{eq} / 1 \mathrm{NaOH}$ volume. This means that more $\mathrm{Na}^{+}$ions in the sulfonated polyvinyl chloride cation exchanger can exchange with more calcium and magnesium ions in wastewater.

Table-1. The sulfonated polyvinyl chloride cation exchanger modifications reaction properties

\begin{tabular}{|c|c|c|c|c|c|c|c|}
\hline \multirow{2}{*}{ № } & \multicolumn{2}{|c|}{$\begin{array}{c}\text { Modifier, } \\
\text { wt.\% }\end{array}$} & $\begin{array}{c}\text { Weight } \\
\text { received } \\
\text { sulfonic cation } \\
\text { exchanger, g }\end{array}$ & $\begin{array}{c}\text { SChV by } \\
\text { PaOH, } \\
\mathrm{mg} \div \text { eq } \\
/ 1\end{array}$ & $\begin{array}{c}\text { Sulfur } \\
\text { strength, } \\
\%\end{array}$ & $\begin{array}{c}\text { Selectivity, } \\
\%\end{array}$ & $\begin{array}{c}\text { Limit } \\
\text { strength } \\
\text { at break, } \\
\mathrm{kg} / \mathrm{cm}^{2}\end{array}$ \\
\hline 1 & 10.0 & 7.0 & 10.55 & 1.78 & 98 & 95 & 180 \\
\hline 2 & 9.0 & 8.0 & 10.87 & 2.25 & 98 & 96 & 190 \\
\hline 3 & 8.0 & 9.0 & 11.07 & 3.58 & 95 & 96 & 200 \\
\hline 4 & 7.0 & 10.0 & 11.28 & 3.78 & 96 & 97 & 205 \\
\hline
\end{tabular}

The following noticeable aspects are that these four type sulfonated polyvinyl chloride cation exchanger have just over $95 \%$ fur strength and selectivity, stating that these modifications are very strong under extremely environment, can reduce $\mathrm{Ca}^{+2}$ and $\mathrm{Mg}^{+2}$ ions wastewater at over 96 percentage. Lastly information, fours sulfonated polyvinyl chloride cation exchanger has more limit strength at break with $205 \mathrm{~kg} / \mathrm{cm}^{2}$ with compared others (Table 1). 


\section{Results and Discussions}

\subsection{Thermodynamics}

Figure 1 and 2 indicate that the sorption kinetics of calcium and magnesium ions on the sulfonated polyvinyl chloride cation exchanger depends on temperature and concentration. It can be seen that the sorption of metal ions in the initial stages increases, after 10 second this trend remained stable, this time is critic trans time, in which $\mathrm{Ca}^{2+}$ and $\mathrm{Mg}^{2+}$ ions reached high sorption rate. It is clear from these figures when the temperature increase the number of absorbed $\mathrm{Ca}^{2+}$ and $\mathrm{Mg}^{2+}$ ions also growth because there is mainly chemisorption.

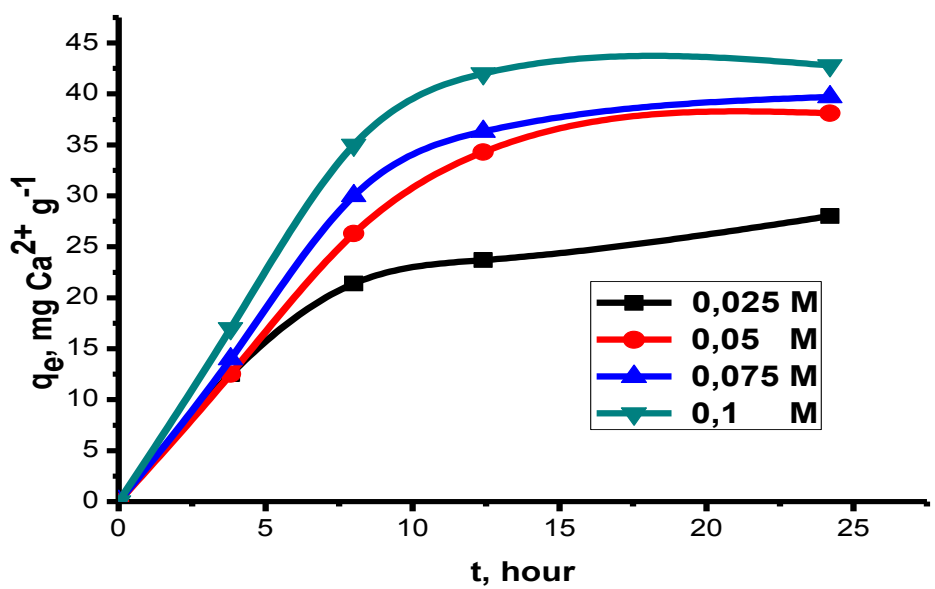

Fig. 1. Kinetics of adsorbed $\mathrm{Ca}^{2+}$ ions on sulfonated polyvinyl chloride cation exchanger at 313 $\mathrm{K}$ temperature.

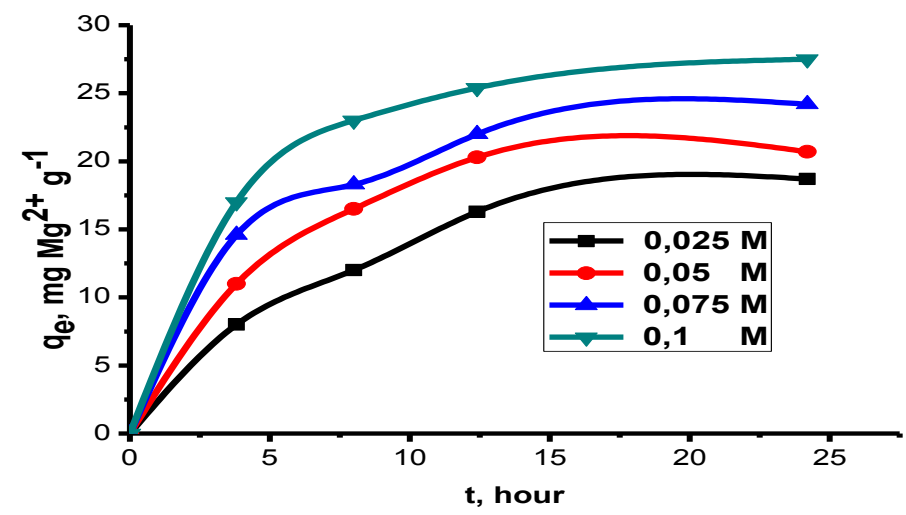

Fig.2. Kinetics of adsorbed $\mathrm{Mg}^{2+}$ ions on sulfonated polyvinyl chloride cation exchanger at 313 K temperature

Physical sorption does not require temperature but chemisorption depend on temperature. If the temperature goes up the chemisorption also increase as a result absorption rate of $\mathrm{Ca}^{2+}$ and $\mathrm{Mg}^{2+}$ ions reach high level. Consequently, the sorption 
of the metal ions occurs due to $\mathrm{Ca}^{2+}$ and $\mathrm{Mg}^{2+}$ ions exchange with sodium ions which located in the sulfonic cation exchange. The sorption kinetics of calcium and magnesium ions on the ion on sulfonated polyvinyl chloride cation exchanger at $313 \mathrm{~K}$ temperature is also depend on concentrations variations. At glance below graphs it was shown 0.1 and $0.075 \mathrm{M}$ concentrations $\mathrm{Ca}^{2+}$ and $\mathrm{Mg}^{2+}$ ions have high sorption degree because this sulfonic cation exchange have high sorption capacity.

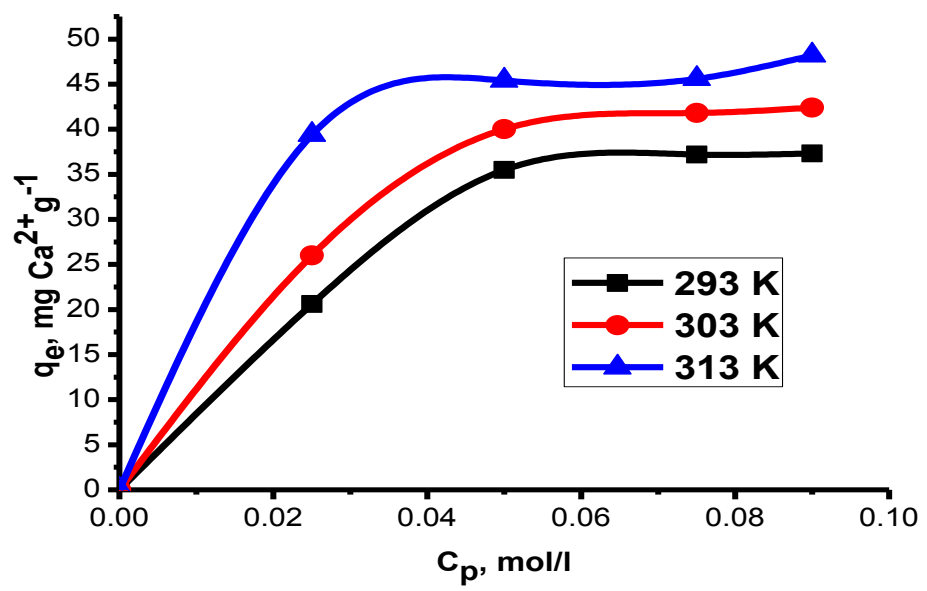

Fig.3. Sorption isotherms of $\mathrm{Ca}^{2+}$ ions in without sulfonated polyvinyl chloride cation exchanger solutions at different temperatures ( 24 hours)

Figure 3 and 4 reveal that the sorption isotherms of $\mathrm{Ca}^{2+}$ and $\mathrm{Mg}^{2+}$ ions with sulfonated polyvinyl chloride cation exchanger depends on concentrations and temperatures. In this research all experiments were done at 293, 303 and $313 \mathrm{~K}$.

The thermodynamic functions of sorption isotherms were determined from the dependence of the equilibrium constants of the ion-exchange sorption process on temperature according to the equation $\Delta \mathrm{G}=-\mathrm{RT} \operatorname{lnK}$. The free energy of the system $\Delta \mathrm{G}=\Delta \mathrm{H}-\mathrm{T} \Delta \mathrm{S}$, from which the value the $\Delta \mathrm{H}$ and $\Delta \mathrm{S}$ was found. According to the results of the thermodynamic study, the values of the free energy for ion exchange were determined, which $\Delta \mathrm{G}$ were $-7.7 \mathrm{KJ} / \mathrm{mol}$ for $\mathrm{Ca}^{2+}$ ions, and $-9.9 \mathrm{KJ} / \mathrm{mol}$ for $\mathrm{Mg}^{2+}$ ions.

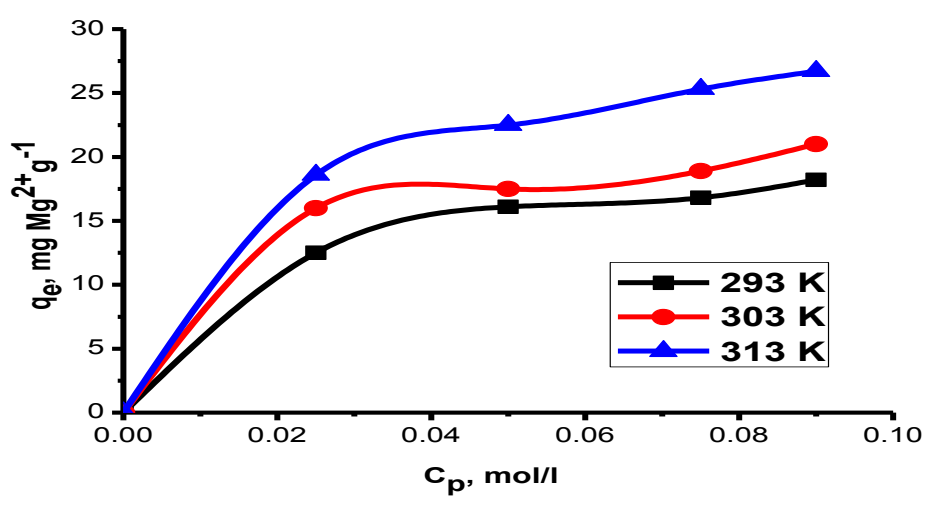

Fig. 4. Sorption isotherms of $\mathrm{Mg}^{2+}$ ions in in without sulfonated polyvinyl chloride cation exchanger solutions at different temperatures (24 hours) 
Changes in the entropy of the system are positive, 43 and $48 \mathrm{~J} / \mathrm{mol}$ for $\mathrm{Ca}^{2+}$ and $\mathrm{Mg}^{2+}$ ions respectively. Negative values of free energy and positive value of the change in the enthalpy show that the ion exchange on the cation exchanger occurs spontaneously. This indicates that the sorption degree of $\mathrm{Ca}^{2+}$ ions in the sulfonated polyvinyl chloride cation exchanger is higher than $\mathrm{Mg}^{2+}$ ions. This phenomenon can be explained by the high affinity of calcium ions to the sulfur group in the cation exchanger. Positive value of the change in the enthalpy reveals the sorption of $\mathrm{Ca}^{2+}$ and $\mathrm{Mg}^{2+}$ ions endothermic, it means that if the temperature growths the sorption degree of these ions also increases.

\subsection{Electrochemical Impedance Spectroscopy}

Electrochemical impedance spectroscopy experiments can determine kinetics of electrochemical processes of sorption of $\mathrm{Ca}^{2+}$ ions in sulfonated polyvinyl chloride cation exchanger and how can change of kinetic properties of $\mathrm{Ca}$ sulfonated polyvinyl chloride molecule on different temperatures and concentration. Nyquist plots single semicircles were measured in absence and presence of sulfonated polyvinyl chloride cation exchanger on different concentration (Fig. 5). The impedance parameters determined from these Nyquist plots single semicircles and listed in Table I. It is clear from Fig. 5 Nyquist plot is very little in the absence of sulfonated polyvinyl chloride cation exchanger solution, means that in solution charge transfer is not control, there are many calcium ions which cannot connect with any molecules, they are free. When the sulfonated polyvinyl chloride cation exchanger added in $\mathrm{Ca}^{+2}$ solution Nyquist plots single semicircle was changed depend on its concentration because charge transfer in $\mathrm{Ca}^{+2}$ solution was controlled by the sulfonated polyvinyl chloride cation exchanger. $\mathrm{Ca}^{+2}$ ions were adsorbed on the sulfonated polyvinyl chloride cation exchanger and connected oxygen ions as a result there were not free $\mathrm{Ca}^{+2}$ ions. All $\mathrm{Ca}^{+2}$ ions were fully adsorbed on the sulfonated polyvinyl chloride cation exchanger. In high concentration Nyquist plots single semicircle is larger than lower concentration because increase a number of polymer molecules can growth sorption capacity of solution. These results show this sulfonated polyvinyl chloride cation exchanger is high capacity adsorbed for $\mathrm{Ca}^{+2}$ ions.

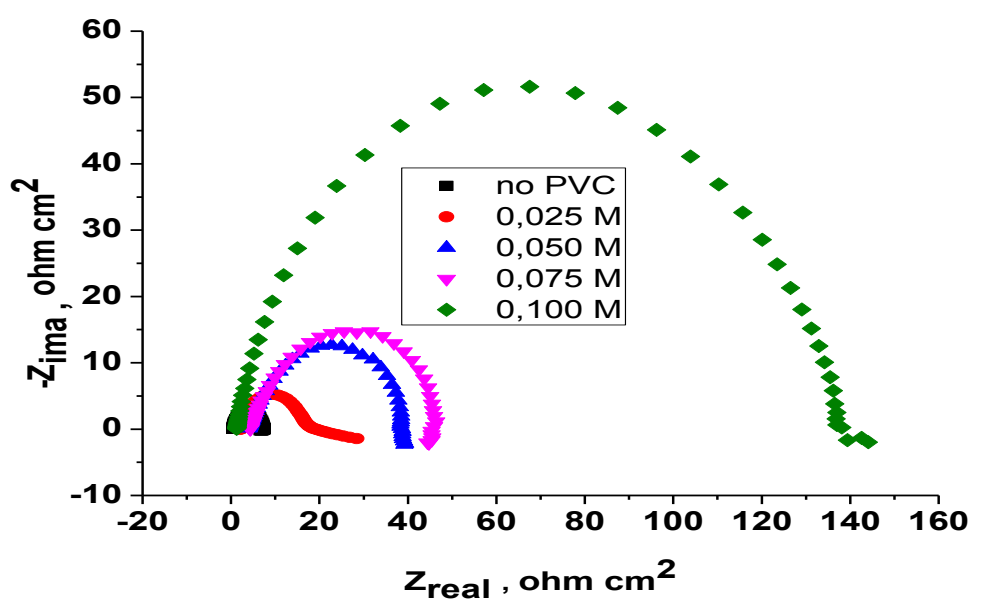

Fig.5. Nyquist plot of sulfonated polyvinyl chloride cation exchanger ( $\mathrm{T}=313 \mathrm{~K})$. 
The impedance results were analyzed by using the equivalent circuit model shown in Figure 6 consisting of $\mathrm{R}_{\mathrm{s}}$ (solution resistance), CPE (constant-phase element) parallel to the $\mathrm{R}_{\mathrm{ct}}$ (charge transfer resistance). The charge-transfer resistances $\left(\mathrm{R}_{\mathrm{ct}}\right)$ were calculated by the difference in impedance at the lower and higher frequencies. The highest $R_{c t}$ is 155,64 $\Omega / \mathrm{cm}^{2}$ obtained on $0,1 \mathrm{M}$ concentration.

The impedance spectra were analyzed by fitting to the equivalent circuit model shown in Fig. 6, which has been used previously to adequately model the sulfonated polyvinyl chloride cation exchanger. In this equivalent circuit, the solution resistance is shorted by a constant phase element (CPE) that is placed in parallel to the charge transfer resistance. The CPE is used in place of a capacitor to compensate deviations from ideal dielectric behavior arising from the inhomogeneous nature of the electrode surfaces. The impedance of the CPE is given by

$$
\mathrm{Z}_{\mathrm{CPE}}=\mathrm{Y}_{0}-1(\mathrm{j} \omega)^{-\mathrm{n}}
$$

where $\mathrm{Y}_{0}$ and $\mathrm{n}$ stand for the CPE constant and exponent, respectively, $\mathrm{j}=(-1)^{1 / 2}$ is an imaginary number, and $\omega$ is the angular frequency in $\operatorname{rad~s}^{-1}(\omega=2 \pi \mathrm{f})$, where $\mathrm{f}$ is the frequency in Hz. The corresponding electrochemical parameters are presented in Table 1 and reveal that the inhibitor increased the magnitude of $R_{c t}$, with corresponding decrease in the double layer capacitance $\left(\mathrm{C}_{\mathrm{dl}}\right)$. The increase in $\mathrm{R}_{\mathrm{ct}}$ values in inhibited systems, which corresponds to an increase in the diameter of the Nyquist semicircle, confirms the corrosion inhibiting effect of inhibitor.

Table-2. Electrochemical parameter for sulfonated polyvinyl chloride cation exchanger $(\mathrm{T}=313 \mathrm{~K})$

\begin{tabular}{|c|c|c|c|c|c|}
\hline $\begin{array}{c}\text { Cation } \\
\text { exchanger }\end{array}$ & $\begin{array}{c}\text { Concentrations, } \\
\mathrm{M}\end{array}$ & $\mathrm{R}_{\mathrm{s}, \Omega} \Omega / \mathrm{cm}^{2}$ & $\mathrm{R}_{\mathrm{ct},} \Omega / \mathrm{cm}^{2}$ & $\mathrm{Y}_{0, \mu \mathrm{ff} / \mathrm{sm}^{2}}$ & $\mathrm{C}_{\mathrm{dl}}, \mu \mathrm{f} / \mathrm{sm}^{2}$ \\
\hline No & - & 2.02 & 4.00 & 485 & 154 \\
\hline \multirow{2}{*}{$\begin{array}{c}\text { PVC-SC } \\
\text { sulfonic } \\
\text { cation } \\
\text { exchanger }\end{array}$} & 0.025 & 0.85 & 35.38 & 142 & 58.54 \\
\cline { 2 - 6 } & 0.05 & 0.78 & 42.58 & 124 & 51.25 \\
\cline { 2 - 6 } & 0.075 & 0.71 & 54.74 & 75 & 41.32 \\
\hline
\end{tabular}

Table-3. The electrochemical impedance parameter for sulfonated polyvinyl chloride cation exchanger $(\mathrm{T}=313 \mathrm{~K})$

\begin{tabular}{|c|c|c|c|c|c|c|}
\hline $\begin{array}{c}\text { Concentration, } \\
\mathrm{mg} / \mathrm{l}\end{array}$ & \multicolumn{2}{|c|}{$\mathrm{Z}_{\bmod }, \mathrm{ohm}$} & \multicolumn{2}{c|}{ Freq, $\mathrm{Hz}$} & \multicolumn{2}{c|}{$\mathrm{Z}_{\text {phz }},{ }^{0} \mathrm{C}$} \\
\cline { 2 - 7 } & $\min$ & $\max$ & $\begin{array}{c}\min , \\
\mathrm{kHz}\end{array}$ & $\begin{array}{c}\max , \\
\mathrm{mHz}\end{array}$ & $\min$ & $\max$ \\
\hline $\mathrm{No}$ & 0.421 & 7.54 & 20.12 & 20.01 & -0.01 & 1.256 \\
\hline 0.025 & 2.154 & 28.32 & 50.78 & 15.47 & -37.45 & 2.821 \\
\hline 0.05 & 1.254 & 38.74 & 55.45 & 39.78 & -41.46 & 3.675 \\
\hline 0.075 & 4.254 & 46.32 & 79.54 & 55.45 & -45.85 & 5.691 \\
\hline 0.1 & 1.154 & 144.51 & 80.24 & 80.87 & -65.54 & 7.786 \\
\hline
\end{tabular}

The observed decrease in $\mathrm{C}_{\mathrm{dl}}$ values, which normally results from a decrease in the dielectric constant and/or an increase in the double-layer thickness, can be attributed to the adsorption of $\mathrm{Ca}^{+2}$ ions (with lower dielectric constant compared to the displaced adsorbed water molecules) onto sulfonated polyvinyl chloride cation exchanger.

The double layer capacitance $\left(\mathrm{C}_{\mathrm{dl}}\right)$ can be calculated using the following equation: 


$$
C_{d l}=\frac{Y \omega^{n-1}}{\sin \left(n\left(\frac{\pi}{2}\right)\right)}
$$

where, $\Omega$ is the angular frequency $\left(\Omega=2 \pi \mathrm{f}_{\max }\right)$ at which the imaginary part of the impedance $\left(-Z_{\text {im }}\right)$ is maximal, and $n$ is the phase shift, which can be used as a gauge of the heterogeneity or roughness of the mild steel surface.

In the same manner, a decrease in $\mathrm{C}_{\mathrm{dl}}$ is attributed to decrease in dielectric constant and increase in the thickness of the electrical double layer, suggesting that the $\mathrm{Ca}^{+2}$ ions are adsorbed at PVC-SC sulfonic cation exchanger.

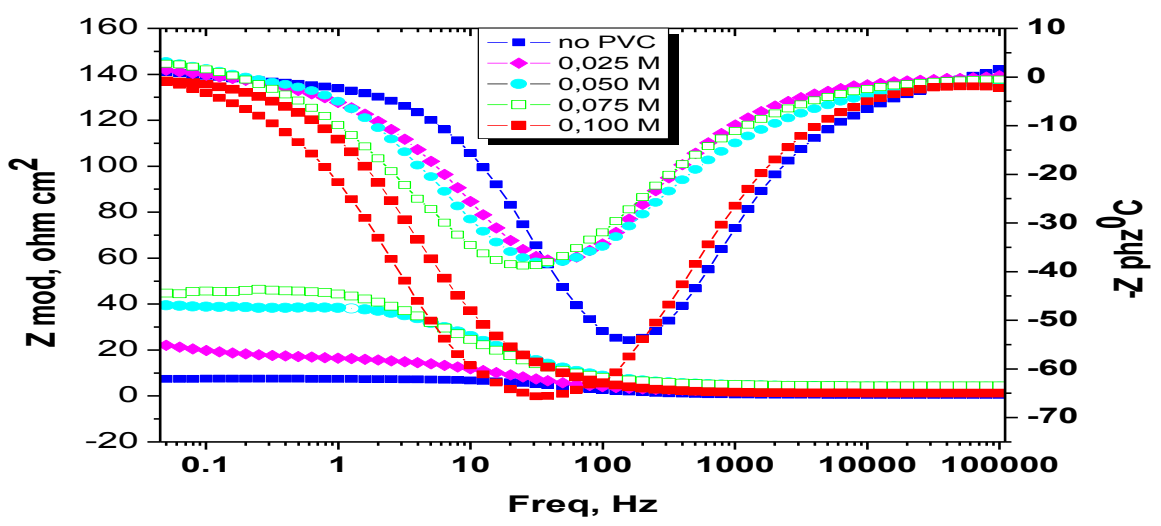

Fig. 6. Bode plots for sulfonated polyvinyl chloride cation exchanger

The thickness of this protective layer (d) is correlated with $\mathrm{C}_{\mathrm{dl}}$ by the following equation,

$$
\mathrm{C}_{\mathrm{dl}}=\frac{\varepsilon \varepsilon_{0} \mathrm{~A}}{\mathrm{~d}}
$$

where $\varepsilon$ is the dielectric constant and $\varepsilon_{0}$ is the permittivity of free space, and $A$ is the surface area of the electrode.

The Bode phase angle plots (Figure 7) show single maximum (one time constant) at intermediate frequencies, broadening of this maximum in the presence of sulfonated polyvinyl chloride cation exchanger accounts for the formation of a protective layer on the electrode surface. Moreover, there is only one phase maximum in Bode plot (Figure 7) sulfonated polyvinyl chloride cation exchanger, which indicates only one relaxation process, which would be the charge transfer process, taking place at the metal-electrolyte interface.

Electrochemical results $\eta \%$ are in good agreement with the results $\eta \%$ obtained by weight loss experiment. The Bode phase angle plots were shown in Fig. 8 recorded for sulfonated polyvinyl chloride cation exchanger to explain the various phenomena taking place at the metal/solution interface. The increase in absolute impedance at low frequencies in the Bode plot confirms the higher protection with the increasing of sulfonated polyvinyl chloride cation exchanger concentration. In our investigation, minimum and maximum of $\mathrm{Z}_{\mathrm{mod}}$,ohm, Freq, $\mathrm{Hz}$ and $\mathrm{Z}_{\mathrm{phz}},{ }^{0}$ reported growth rate during concentration increasing as a result $\mathrm{Ca}^{+2}$ sorption of PVC-SC sulfonic cation exchanger is going up and being stable. 
Table-4. The energy values of global reactivity descriptors for $\mathrm{Na}, \mathrm{Ca}, \mathrm{Mg}$ sulfonated polyvinyl chloride molecules

\begin{tabular}{|c|c|c|c|}
\hline \multirow{2}{*}{ Parameter } & $\begin{array}{c}\text { Na sulfonated } \\
\text { polyvinyl chloride }\end{array}$ & $\begin{array}{c}\text { Ca sulfonated } \\
\text { polyvinyl chloride }\end{array}$ & $\begin{array}{c}\text { Mg sulfonated } \\
\text { polyvinyl chloride }\end{array}$ \\
\cline { 2 - 4 } & \multicolumn{3}{|c|}{ Value (eV) } \\
\hline Chemical Hardness, $\eta$ & 0.165 & 0.917 & 0.694 \\
\hline Electronegativity, $\chi$ & -1.165 & -0.917 & -0.649 \\
\hline Electronic chemical potential, $\mu$ & 3.839 & 3.795 & 21.925 \\
\hline Global electrophilicity Index, $\omega$ & 44.469 & 7.854 & 348.353 \\
\hline Chemical Softness, $s$ & 3.016 & 0.545 & 0.724 \\
\hline
\end{tabular}

\section{Conclusions}

Sulfonated polyvinyl chloride cation exchanger was firstly synthesized based on local low cost product: plastic polyvinyl chloride, powdered sulfur and sulfurcontaining compounds. It was proven by research results that sulfonated polyvinyl chloride cation exchanger is low cost, very effective water softening and cleaning polymer materials, easily synthesized, biodegradable.

The thermodynamic research results show that the sorption of $\mathrm{Ca}^{2+}$ and $\mathrm{Mg}^{2+}$ ions on sulfonated polyvinyl chloride cation exchanger is spontaneously and endothermic; it has great capacity for $\mathrm{Ca}^{2+}$ and $\mathrm{Mg}^{2+}$ ions; during the sorption process of $\mathrm{Ca}^{2+}$ and $\mathrm{Mg}^{2+}$ ions on sulfonated polyvinyl chloride cation exchanger the chemisorption is dominated than physical sorption.

DFT calculation results of synthesized the sulfonated polyvinyl chloride cation exchanger indicate that the energy band gap into LUMO and HOMO molecular orbitals of $\mathrm{Na}, \mathrm{Ca}$ and $\mathrm{Mg}$ sulfonated polyvinyl chloride is lower, respectively, $0.331 \mathrm{eV}, 0.917 \mathrm{eV}$ and $1.389 \mathrm{eV}$, this means that $\mathrm{Na}, \mathrm{Ca}, \mathrm{Mg}$ sulfonated polyvinyl chloride molecules shows that this molecular structure is lower stability and more reactivity, means that they are biodegradable and easily recycling polymer.

Sulfonated polyvinyl chloride cation exchanger in Muborak oil and gas LTD company (Uzbekistan) was used for softening waste water from heavy metals.

Electrochemical impedance spectroscopy results show this sulfonated polyvinyl chloride cation exchanger is high capacity adsorbed for $\mathrm{Ca}^{+2}$ and $\mathrm{Mg}^{+2}$ ions.

\section{References}

1. M. Caluwe, T. Dobbeleers, D. Daens, L. Geuens, R. Blust, J. Dries, SBR treatment of tank truck cleaning wastewater: sludge characteristics, chemical and ecotoxicological effluent quality, Environ. Technol, 39, p. 2524. (2018)

2. W. Cao, Z. Dang, X.Q. Zhou, X.Y. Yi, P.X. Wu, N.W. Zhu, G.N. Lu, Removal of sulphate from aqueous solution using modified rice straw: preparation, characterization and adsorption performance, Carbohydr. Polym., 85 p. 571. (2011).

3. Chinese NEPA, Water and Wastewater Monitoring Methods, (fourth ed.), Chinese Environmental Science Publishing House, Beijing, China, p.52. (2012).

4. UNEP, Water and Wastewater Reuse. An Environmentally Sound Approach for Sustainable Urban Water Management., USA. (2013).

5. Kerrn-Jespersen JP, Henze, M, Strube R, Biological Phosphorus Release and Uptake Under Alternating Anaerobic and Anoxic Conditions in a Fixed-film Reactor. Water Research, 28., p.1253. (1994) 
6. Asatekin, A.M. Mayes, Oil industry wastewater treatment with fouling resistant membranes containing amphiphilic comb copolymers, Environ. Sci. Technol. 43, p. 4487. (2009).

7. P.D. Fletcher, L.D. Savory, F. Woods, A. Clarke, A.M. Howe, Model study of enhanced oil recovery by flooding with aqueous surfactant solution and comparison with theory, Langmuir, 31, p. 3076. (2015).

8. H. Guo, F. You, S. Yu, L. Li, D. Zhao, Mechanisms of chemical cleaning of ion exchange membranes, a case study of plant-scale electrodialysis for oily wastewater treatment, J. Membr. Sci, 496, p. 310. (2015).

9. G. Han, J.S. de Wit, T.-S. Chung, Water reclamation from emulsified oily wastewater via effective forward osmosis hollow fiber membranes under the PRO mode, Water Res., 81, p. 54. (2015).

10. G. Liu, S. Yu, H. Yang, J. Hu, Y. Zhang, B. He, et al., Molecular mechanisms of ultrafiltration membrane fouling in polymer-flooding wastewater treatment: role of ions in polymeric fouling, Environ. Sci. Technol. 50, p. 1393. (2016).

11. E. Berdimurodov et al., "Electrochemical Frequency Modulation and Reactivation Investigation of Thioglycolurils in Strong Acid Medium", Advanced Materials Research, 1154, p. 122. (2019)

12. Elyor Berdimurodov, J Wang, Abduvali Kholikov, Khamdam Akbarov, Bakhtiyor Burikhonov, Nurbik Umirov, Investigation of a New Corrosion Inhibitor Cucurbiturils for Mild Steel in 10\% Acidic Medium, Advanced Engineering Forum, Trans Tech Publications, 18, p. 21. (2016).

13. Elyor Berdimurodov, Abduvali Kholikov, Khamdam Akbarov, Innat Nakhatov, Nigora Kh Jurakulova, Nurbek Umirov, Adsorption Isotherm and SEM Investigating of Cucurbit [n] Urils Based Corrosion Inhibitors with Gossypol for Mild Steel in Alkaline Media Containing Chloride Ions, Advanced Engineering Forum, Trans Tech Publications, vol. 23, p. 13. (2017).

14. Elyor Berdimurodov, Abduvali Kholikov, Khamdam Akbarov, D Nuriddinova, Polarization Resistance Parameters of Anti-Corrosion Inhibitor of Cucurbit [N] Urils and Thioglycolurils in Aggressive Mediums, Advanced Engineering Forum, Trans Tech Publications, (26), p. 74. (2018)

15. Y.I. Chang, W.Y. Cheng, L. Jang, A new method of preparing superabsorbent PVF porous foam through the simultaneous acidification of water glass solution -Aspect of environmental protection, J. Appl. Polym. Sci. (10), , p. 39894. (2014).

16. P.R. Gogate, A.B. Pandit, A review of imperative technologies for wastewater treatment I: oxidation technologies at ambient conditions, Adv. Environ. Res., 8, p. 501. (2004).

17. G. Pliego, J.A. Zazo, S. Blasco, J.A. Casas, J.J. Rodriguez, Treatment of highly polluted hazardous industrial wastewaters by combined coagulation-adsorption and high-temperature Fenton oxidation, Ind. Eng. Chem. Res. 51, p. 2888. (2012).

18. Praveen K. Bayannavar, Madivalagouda S. Sannaikar, S. Madan Kumar, Sanjeev R. Inamdar, Saba Kauser J. Shaikh, Aravind R. Nesaragi, Ravindra R. Kamble, Synthesis, X-ray characterization, DFT studies and Hirshfeld surface analysis of new organic single crystal: 2-(4-Methoxyphenyl)-4-\{[2'-(1H-tetrazol-5-yl)biphenyl-4-yl] methyl -2,4-dihydro-3H-1,2,4-triazol-3-one (MTBT), Journal of Molecular Structure, 1179: pp 809-819 (2019).

19. Thammarat Aree, Suchada Jongrungruangchok, Structure-antioxidant activity relationship of $\beta$-cyclodextrin inclusion complexes with olive tyrosol, hydroxytyrosol and oleuropein, Deep insights from X-ray analysis, DFT calculation and DPPH assay, Carbohydrate Polymers, , 199 pp 661-669, (2018) 